\title{
A 5 year trend and predictors of preterm births in single referral centre of the Greater Kuala Lumpur, Malaysia
}

\begin{abstract}
Objective: To determine the trend in incidence of preterm birth over five years and its predictors in a single centre.
\end{abstract}

Design: A cross sectional study using electronic data from a Total Hospital Information System (THIS) and computerized birth registry system.

Setting: A single teaching and referral hospital in the Greater Kuala Lumpur, Malaysia.

Population or Sample: All livebirths delivered in the centre from January 2011 to December 2015 weighing $\geq 500 \mathrm{~g}$

Methods: Logistic regressions with backward likelihood ratio were used.

Main outcome measures: Preterm live birth and live term babies.

Results: 31,405 live births were included. There was almost $20 \%$ increment in the incidence of preterm births between 2011 and 2012 which then gradually decreased until 2015. Maternal age of 20-34 years (OR 0.7, 95\% CI 0.7-0.8) was noted as a protective factor. The highest risk level of the pregnancy (OR 2.83, 95\% CI 2.3-3.4), multiple pregnancy (OR 2.2, 95\% CI 1.8-2.6), low birth weight (OR 18.7, 95\% CI 17.1-20.4) and male infant (OR 1.3, 95\% CI 1.2-1.5) were noted as risk factors.

Conclusions: The incidence showed an upward trend between 2011 and 2012 then a gradual decrease until 2015 with a similar pattern reported by national data. The predictors of preterm birth in the study centre were birth weight, risk level of the pregnancy, multiplicity of pregnancy, maternal age and infant gender. Continuum of care using the risk level coding assessment must be enhanced at the primary care level especially for appropriate referral and co-management at a referral centre (secondary or tertiary hospital).

Keywords: preterm birth, incidence, determinants, predictors

\section{Introduction}

As the leading cause of prenatal morbidity and mortality, preterm birth had been a public health concern and the focus of World Health Organization (WHO) since 2010 under the Millenium Development Goal (MDG) and Sustainable Development Goal (SDG) indicators. Globally, it is the second cause of death for children under five, after pneumonia. ${ }^{1-4}$ The Global Action Report reported an increasing trend with Malaysia at the $47^{\text {th }}$ place in $2010 .^{2}$ Its multifactorial causes include social factors such as racial disparity among the blacks and hispanics, ${ }^{5}$ tobacco and alcohol use and nature of job, ${ }^{6}$ maternal height, ${ }^{7}$ maternal weight, ${ }^{8}$ maternal age ${ }^{9,10}$ and infant gender. ${ }^{9-11}$ Increasing subfertility among women of reproductive age in developed and developing countries $(5 \%-26 \%)$ and men $(14-22 \%)^{12}$ led to usage of reproductive technology which was linked to multiple gestation and preterm birth. ${ }^{12,13}$

Maternity care is provided through both public and private sectors in Malaysia. In the public sector, community health centres at the primary care level provide the preconceptional and antenatal maternity care services according to specific guidelines. Indicated high risk mothers are referred to district or state hospitals (secondary or tertiary levels as referral centres). Preterm birth prevention starts here with preconceptional advice and thorough exploration into a couple's risk
Volume 4 Issue 6 - 2018

Rosnah Sutan,' Nur Ezdiani Mohamed,' Zaleha Abdullah Mahdy, ${ }^{2}$ Shareena Ishak, ${ }^{3}$ Khadijah Shamsuddin,' Idayu Badilla Idris, ${ }^{2}$ Shuhaila Ahmad, ${ }^{2}$ Rohana Jaafar, ${ }^{3}$ Aniza Ismail,' Saperi Sulong ${ }^{4}$

'Community Health Department, Universiti Kebangsaan Malaysia, Malaysia

${ }^{2}$ Obstetric and Gynecology Department, Universiti Kebangsaan Malaysia, Malaysia

${ }^{3}$ Pediatrics Department, Universiti Kebangsaan Malaysia, Malaysia ${ }^{4}$ Medical Record Department, Universiti Kebangsaan Malaysia, Malaysia

\section{Correspondence: Rosnah Sutan, Public Health Physician (Family Health Group), Community Health Department, Universiti Kebangsaan Malaysia Medical Centre, Bandar Tun Razak Cheras 56000 Kuala Lumpur, Malaysia, Tel +603- 914558966,0193212256,Email rosnah_suten@yahoo.com, rosnah.suten@ppukm.ukm.edu.my}

Received: October 05, 2018 | Published: December 03, 2018 factors. Antenatally, using proper maternal risk level coding, mothers are screened and those with red code are given antenatal steroid treatment before being referred to secondary or tertiary care. ${ }^{14}$ The incidence of preterm birth is captured through hospitals and reported annually. The third National Obsterics Registry report in 2013, ${ }^{15}$ showed increasing preterm birth incidence over the three years period from 2010 to $2012(8.1 \%, 10.4 \%$ and $11.3 \%$ respectively). In the report, preterm birth rates were high among the indigenous population in Peninsular Malaysia, mothers at the extremes of age, parity $>6$, and mothers with preeclampsia, eclampsia and underlying heart disease. ${ }^{15}$

Preterm birth is not only related to adverse health outcome involving behaviour, neurodevelopment, psychosocial factors and growth, ${ }^{2,6,16}$ but also poses financial and societal burden to the health systems and country. The WHO has recommended that antenatal corticosteroids be given to women at risk from 24 to 34 weeks following certain criteria. ${ }^{17}$ An analysis across 39 countries estimated that countries with very high human development index will be able to reduce $5 \%$ of their preterm birth rate if the selected interventions are applied locall. The research question here is, is there any other factors that need intervention? This study aimed at describing the incidence trend of preterm births over a five year period and its predictors in a tertiary centre based on conceptual framework derived (Figure 1). 


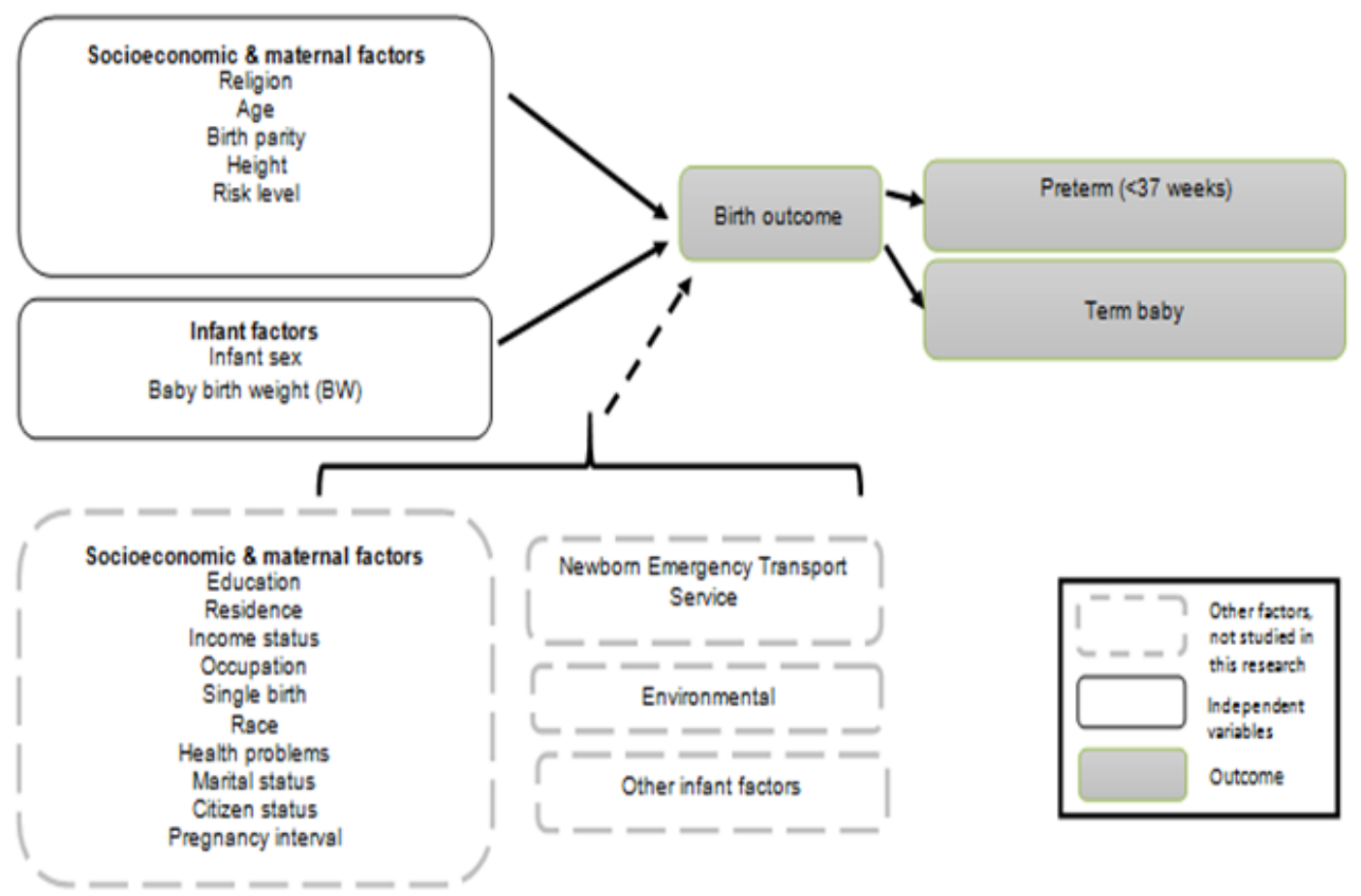

Figure I Conceptual framework of the study

\section{Methodology}

This was a cross sectional study done using data obtained from the Total Hospital Information System (THIS), an electronic data system of a teaching hospital labour room. Universiti Kebangsaan Malaysia Medical Centre (UKMMC) is one of the main referral centres in the country. Birth data were recorded in both manual case records and an electronic data system. Data captured by the system were maternal demographic and obstetric information, newborn profiles and birth outcomes. The birth outcomes reported were neonatal fitness for discharge to mother, NICU admission and stillbirth. Details of newborn profiles such as genetic and chromosomal abnormalities, growth restriction and physical abnormalities were not recorded in the birth census. Information such as maternal medical history, comorbidity and previous obstetric history were also not recorded in the electronic data system, but documented in the antenatal record books or hospital medical records. Data were entered into the electronic system by nurses based on the admission sheet and information in the medical records.

The study population covered all births delivered in the centre from January 2011 to December 2015. The sampled population included all livebirths born in the centre during the same period with birth weight more than $500 \mathrm{~g}$. The outcome measures in this study were preterm and term live births. Preterm births were defined as live births before 37 completed weeks of pregnancy based on the WHO classification. ${ }^{18}$ Cases with incomplete birth and maternal parameters were excluded from analysis. Incidence of preterm birth was calculated as the number of preterm live births within a year divided by the number of live births calculated annually between 2011 and 2015. Table 1 shows the prevalence of preterm birth in UKMMC from 2011-2015.

The independent variables extracted from this database were the socio-maternal factors and birth outcome details as outlined in
Figure 2. All variables were categorised based on literature. All were dichotomised except the risk level and maternal age. Age was divided into three groups where extremes of age were defined as $<20$ and $\geq 35$ years old. ${ }^{19}$ Age was cross checked with the National Registration Identification Number. Religion-wise, the women were divided into Muslims and Non-muslims as data for non-muslims were small. Risk level was based on the risk approach colour coding system devised by the Ministry of Health. It is used in antenatal care to differentiate between high risk and low risk pregnant mothers. The coding starts from white followed by traffic light colours with red indicating mother with highest pregnancy risk and need to be referred to hospital for shared care between the obstetrician and family health specialist. Maternal height was divided into below $145 \mathrm{~cm}$ and $145 \mathrm{~cm}$ and above, based on the risk factor identified in the same guideline which states that mothers with height of $145 \mathrm{~cm}$ or less should be tagged with the green risk level code and managed at least by medical officers with subsequent follow-up co-managed with community/clinical nurse. ${ }^{20}$ This study was funded under the University Research Grant (GUP2014-089). It is a sub-study under maternal and neonatal disease burden in UKMMC, a record-linkage study project.

Data was analysed using the Statistical Package for Social Sciences (Version 21). Pregnancy outcomes were compared using univariate and multivariate statistical analyses. Simple logistic regression was used to determine the initial association of the bivariates followed by binary logistics regression for multivariate analysis. Backward likelihood ratio logistic regression method was used to enter the predictive determinants in the logistic regression model with level of significance set at $95 \%$. Crude and adjusted odds ratios with $95 \%$ confidence interval (CI) were calculated. Statistical significance was set at a $P$ value of 0.05 . All odds ratios calculated were adjusted for age, religion, maternal height, parity, pregnancy risk level, type of pregnancy, infant gender and infant weight. 


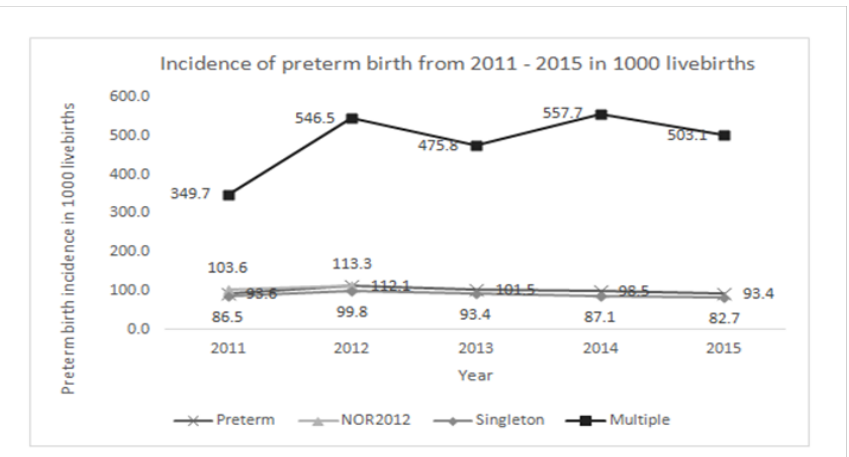

Figure 2 Preterm birth incidence in 1000 live births over a 5 years period in UKMMC

Source of data: preterm, singleton and multiple data trends were calculated from UKMMC deliveries and the NOR (I5) was obtained from the published national report using a similar incidence ratio calculation.

Table I Preterm birth rate by factors in UKMMC

\begin{tabular}{|c|c|c|c|}
\hline & $\begin{array}{l}\text { Number of } \\
\text { live birth }\end{array}$ & $\begin{array}{l}\text { Number of preterm } \\
\text { birth }\end{array}$ & $\begin{array}{l}\text { Preterm birth } \\
\text { rate in } 1000\end{array}$ \\
\hline No of births & 31405 & 3130 & 99.7 \\
\hline \multicolumn{4}{|c|}{ Maternal age (years) } \\
\hline$<20$ & 366 & 53 & 144.8 \\
\hline $20-34$ & 26027 & 2442 & 93.8 \\
\hline$\geq 35$ & 5012 & 635 & 126.7 \\
\hline \multicolumn{4}{|l|}{ Religion } \\
\hline Muslim & 23281 & 2292 & 98.4 \\
\hline Non-muslim & 8124 & 838 & 103.2 \\
\hline \multicolumn{4}{|c|}{ Mother's height $(\mathrm{cm})$} \\
\hline$<145$ & 430 & 59 & 137.2 \\
\hline$\geq 145$ & 30975 & 3071 & 99.1 \\
\hline \multicolumn{4}{|l|}{ Parity } \\
\hline Primid & 12548 & 1350 & 107.6 \\
\hline$\geq 1$ & 18857 & 1780 & 94.4 \\
\hline \multicolumn{4}{|l|}{ Risk Level } \\
\hline White & 28577 & 2645 & 92.6 \\
\hline Green & 1410 & 176 & 124.8 \\
\hline Yellow & 545 & 73 & 133.9 \\
\hline Red & 873 & 236 & 270.3 \\
\hline \multicolumn{4}{|l|}{ Single birth } \\
\hline Yes & 30613 & 2748 & 89.8 \\
\hline No & 792 & 382 & 482.3 \\
\hline \multicolumn{4}{|l|}{ Infant sex } \\
\hline Boy & 16253 & 1719 & 105.8 \\
\hline Girl & 15140 & 1406 & 92.9 \\
\hline \multicolumn{4}{|l|}{ Infant weight } \\
\hline$<2.5 \mathrm{~kg}$ & 3813 & 1885 & 494.4 \\
\hline$\geq 2.5 \mathrm{~kg}$ & 27592 & 1245 & 45.1 \\
\hline
\end{tabular}

Missing data: Data on religion were missing in $40.9 \%$ and further reduced to $12.5 \%$ by imputing those of Malay and Indian Muslim ethnicity as Muslims. Missing data on height were imputed with average height of the relevant country or ethnicity found in literature. ${ }^{21}$

\section{Result}

From 33,292 births captured in the UKMMC database, only 31,405 live births were included for the analysis. The overall preterm birth incidence compared with singleton and multiple preterm incidences over the five years' duration are as in Figure 2 where it showed a variable trend with 20\% increment between 2011 and 2012 and $9.5 \%$ decrement the following year as tabulated in Table 1 . In the multiple logistic regression analyses (Table 2), birth weight was the most significant predictor. The odds of a mother whose baby weighed $<2.5 \mathrm{~kg}$ at birth delivering preterm is 19 times compared to those whose babies weighed $2.5 \mathrm{~kg}$ or more. On the other hand, mothers aged 20-34 years were $26 \%$ less likely to have preterm birth compared to mothers aged 35 years and beyond. Mothers with red code risk levels were almost three times more likely to delivery preterm compared to code white. The odds of a boy being delivered preterm is 1.3 times compared to a girl. Multiple pregnancy increases the risk of preterm birth by more than twice compared to singleton.

Four pairs of independent variables were noted to have interaction, i.e. risk level and singleton status, infant gender and birth weight, infant gender and singleton status, and singleton status and birth weight. There was no multicolinearity among these independent variables. Hosmer and Lemeshow goodness-of-fit test showed that the dataset fits well to the logistic model. The model was able to predict $91.1 \%$ of mothers at risk of preterm birth. Further analyses were done on the pair with interaction with highest odds; singleton status and birth weight. Among babies weighing $<2.5 \mathrm{~kg}$ at birth, mothers with multiple pregnancy have nearly twice the odds of preterm birth, whilst among babies weighing $2.5 \mathrm{~kg}$ or more, the odds were three. On the other hand, singleton pregnancies were $95 \%$ less likely to be born preterm even when birth weight was $<2.5 \mathrm{~kg}$. The interaction difference was small, thus the interaction term can be dropped.

\section{Discussion}

The incidence of preterm birth in the study centre showed about $20 \%$ increment between 2011 and 2012 then decreased gradually until 2015. Our National Obstetric Registries reported similar preterm birth rates that was increasing between 2010 and 2012 (8\% to $11.3 \%) .{ }^{15}$ The decreasing pattern of preterm birth between 2012 and 2013 might be due to a $6.2 \%$ decrease in the national birth rate of that year. ${ }^{22}$ However, the drastic increment of $20 \%$ in the previous year differs from the crude birth rate increment of about $1.1 \%{ }^{23}$ The trend in this study was better than the hospital-based prevalence rate reported in a cohort study in a tertiary teaching hospital in Nigeria which was 120 in 1000 population in $2009^{19}$ as opposed to the incidence in this study centre which never exceeded 115 in 1000 population across the five years. The difference, however, may be due to the policy of the Nigerian teaching hospital which only accepted complicated pregnancy referrals as opposed to our centre which also accepts normal deliveries for undergraduate teaching purposes.

Birth weight was the most significant predictor of preterm birth followed by maternal factors, which were risk level and multiplicity of pregnancy. A study in a province in China did not find any association between birth weight and preterm birth. ${ }^{9}$ Yet, National Obstetrics Registry reported that in 2011 and 2012, almost 60\% of

(10.15406/ipcb.2018.04.00126 
our preterm babies weighed $2.5 \mathrm{~kg}$ or less. ${ }^{15}$ However, the birth weight captured in our centre was the delivered weight which has little use as a predictor in preterm birth; a better predictor is sonographic weight taken at 24 and 34 weeks and its centile at that time. ${ }^{15}$ However, in our study, red code pregnancy risk level is a reliable proxy to birth weight. Our results showed that mothers tagged with red code were almost 3 times more likely to deliver preterm. In the guideline by $\mathrm{MOH}$, mothers who are tagged red can have any of these problems - eclampsia, pre-eclampsia, hypertension with blood pressure $>170 / 110 \mathrm{mmHg}$, symptomatic hypertension with blood pressure $>140 / 90 \mathrm{mmHG}$, symptomatic cardiovasular disease, shortness of breath on minimal exertion, uncontrolled diabetes with ketone in urine, antepartum hemorrhage, symptomatic anemia or $\mathrm{HB} \leq 7 \mathrm{~g} \%$, premature contraction, leaking liquor with no contraction, severe asthmatic attack, seizure or prolonged fever ( $\geq 5$ days) abnormal fetal heart rate $)^{20}$ These are preterm-prone signs and symtoms which can also lead to poorly thriving fetuses. ${ }^{24-27}$
In our study the majority of mothers delivered well within child bearing age (20-34 years old). This is obstetrically healthy as the analysis significantly showed that being pregnant at this age is protective against preterm birth. In USA, the Child Trends Organisation's analysis showed that the proportion of preterm births was increasing for older mothers ranging from 1 to 9 percentage points when moving from mothers of 20-39 years of age to those beyond 45 years old. Early antenatal care was recommended for the high risk group for screening and detection of risk factors, which would then enable preventive measures. This is echoed in the Malaysian guideline as mentioned in our antenatal care manual. ${ }^{5,14}$ The relationship between advanced maternal age and higher risk for preterm birth was also reported in studies in China and Bangladesh ${ }^{9,28}$ while a case-control study in Malaysia showed that younger mothers ( $<20$ years old) were also at risk, with 4.89 times likelihood of delivering preterm. ${ }^{29}$ Surprisingly, the study in Nigeria showed no significant relationship between age and preterm birth. ${ }^{23}$

Table 2 Determinants of preterm births in UKMMC using logistic regression analysis

\begin{tabular}{|c|c|c|c|c|c|c|c|c|}
\hline Variable & Crude OR & $95 \%$ CI OR & $\mathbf{X}^{2 \mathrm{a}}$ & Pvalue ${ }^{a}$ & Adj OR & Adj 95\% CI OR & $\mathbf{X}^{2 \mathrm{a}}$ & Pvalue $^{a}$ \\
\hline Age & & & 55.4 & 0 & & & 32.3 & 0 \\
\hline$<20$ & 1.2 & $(0.9,1.6)$ & $1.0^{\mathrm{b}}$ & 0.317 & 1.1 & $(0.8,1.6)$ & $0.4 \mathrm{~b}$ & 0.508 \\
\hline $20-34$ & 0.7 & $(0.7,0.8)$ & $50.4^{\mathrm{b}}$ & 0 & 0.7 & $(0.7,0.8)$ & $29.0^{\mathrm{b}}$ & 0 \\
\hline$\geq 35$ & 1 & & & & 1 & & & \\
\hline \multicolumn{9}{|l|}{ Religion } \\
\hline Non-muslim & 1.05 & $(1.0,1.2)$ & 1.5 & 0.225 & 1 & $(0.9,1.1)$ & 0.1 & 0.82 \\
\hline Muslim & 1 & & & & 1 & & & \\
\hline \multicolumn{9}{|c|}{ Maternal height } \\
\hline$<145$ & 1.5 & $(1.1,1.9)$ & 6.2 & 0.013 & 0.1 & $(0.7,1.4)$ & 0 & 0.99 \\
\hline$\geq 145$ & 1 & & & & 1 & & & \\
\hline \multicolumn{9}{|l|}{ Parity } \\
\hline Primid & 1.1 & $(1.1,1.2)$ & 14.5 & 0 & 0.9 & $(0.9,1.0)$ & 1.9 & 0.17 \\
\hline$\geq 1$ & 1 & & & & 1 & & & \\
\hline Risk level & & & 235.5 & 0 & & & 106.2 & 0 \\
\hline White & 1 & & & & 1 & & & \\
\hline Green & 1.4 & $(1.2,1.6)$ & $16.3^{\mathrm{b}}$ & 0 & 1.1 & $(0.9,1.3)$ & $0.3^{\mathrm{b}}$ & 0.614 \\
\hline Yellow & 1.5 & $(1.2,1.9)$ & $10.7^{\mathrm{b}}$ & 0.001 & 1.4 & $(1.0,1.8)$ & $4.0^{\mathrm{b}}$ & 0.045 \\
\hline Red & 3.6 & $(3.1,4.2)$ & $267.3^{b}$ & 0 & 2.8 & $(2.3,3.4)$ & $112.6^{\mathrm{b}}$ & 0 \\
\hline \multicolumn{9}{|l|}{ Single birth } \\
\hline No & 9.5 & $(8.2,10.9)$ & 785.3 & 0 & 2.2 & $(1.8,2.6)$ & 75.7 & 0,000 \\
\hline Yes & 1 & & & & 1 & & & \\
\hline \multicolumn{9}{|l|}{ Infant sex } \\
\hline Boy & 1.2 & $(1.1,1.2)$ & 14.6 & 0 & 1.3 & $(1.2,1.5)$ & 45.4 & 0 \\
\hline Girl & 1 & & & & 1 & & & \\
\hline \multicolumn{9}{|l|}{ Baby weight } \\
\hline$<2.5 \mathrm{~kg}$ & 20.7 & $(19.0,22.5)$ & 4938.9 & 0 & 18.7 & $(17.1,20.4)$ & 4124.1 & 0 \\
\hline$\geq 2.5 \mathrm{~kg}$ & 1 & & & & 1 & & & \\
\hline
\end{tabular}

aLikelihood Ratio test

bWald test; $\mathrm{p}<0.05$ 
We also found that the male infant was more likely to be delivered prematurely. This was consistent with a few other studies and reports. ${ }^{2,928}$ A review showed that even throughout life, the female always has a better health outcome; female babies were mostly delivered between 38 and 40 weeks whilst males showed a higher trend to be delivered before 37 and post term up to 42 week..$^{30}$ Another study reported a significant difference in survivorship of male neonates with birth weights ranging from $501 \mathrm{~g}$ to $1500 \mathrm{~g}$, with boys facing a higher risk $(\mathrm{OR}>1.00)$ for most types of adverse outcomes. ${ }^{31}$ This gender difference can possibly be explained by the possibility of influence of sex-linked biochemical processes, including estrogen production from androgen precursors or by interleukin-1.

Subfertility leads to increased usage of technology which in turn increases the susceptibility to multiple pregnancies that runs a higher risk of preterm birth. ${ }^{2,12}$ Our study centre is an assisted fertility centre which explains the high multiple pregnancy rate of almost $500 \%$ compared to global statistics. ${ }^{4}$ Other factors such as parity, maternal height and religion did not appear to be predictors in the final model even though both interval between pregnancy and maternal height were common determinants in preterm births., ${ }^{2,32}$ The study in China also did not find any link between parity and preterm birth in the region. ${ }^{9}$

\section{Limitations}

One of the possible limitation is the accuracy of the information on gestational age that is registered in our THIS. In one study involving inter-hospital data in the United Kingdom, $13 \%$ to $26.8 \%$ of best estimate of gestational age at delivery based on ultrasound scan alone had to be recalculated. ${ }^{20}$ Similarly, gestational age calculation seemed to be a concern in a study in Brazil. ${ }^{33}$ In this study, period of amenorrhoea data was used and cross validation with the diagnosis variable was done. The diagnosis upon discharge after delivery invariably states the gestational age of the pregnancy following ultrasound scan. The ultrasound scan accuracy is influenced by the skill of the operator. Even though the study uses big data for analysis, there is missing and incomplete data per variable, including important variables such as obstetric and antenatal history and maternal marital status. This is consistent with other studies using electronic documentation systems such as in Palestine where completed data ranged between $72.1 \%$ and $95.2 \%{ }^{34}$ Other challenges related to usage of big data in analysis is the existence of correlation merely as a result of the sensitivity and high volume of data. ${ }^{35}$ The $2.0 \%$ missing height data might influence the overall data due to the volume. The result is not generalisable as the study centre is also a fertility centre, and a teaching and referral hospital in the country. The cases accepted might not be similar even with other teaching hospitals in the country.

\section{Conclusion}

The incidence trend of preterm birth in UKMMC showed almost $20 \%$ increment between 2011 and 2012 followed by a gradual decrease until 2015. The predictors of preterm birth in this centre were birth weight, risk level of the pregnancy, multiplicity of pregnancy, age of mother and male infant gender. Usage of the risk level coding must be emphasized and enhanced at the primary care level so that high risk mothers are referred and co-managed appropriately at secondary and tertiary hospitals such as our study centre until delivery.

\section{Acknowledgments}

We would like to acknowledge staff at the Medical Record
Department for assisting in record search, the UKM Ethics Committee for granting the permission to conduct and publish this study, and Dr Zulkarnain Abd Karim for assisting the statistical analysis.

\section{Contribution to Authorship}

RS was involved IN constructing the idea of the write up, conception, planning, supervising the whole process and critically assessing the write up. NEM was involved in the conception, planning, and carrying out the analysis and writing up. ZAM, SI, RJ and SA contributed in the dataset screening. AI and SS helped in data retrieval. KS and IBI helped in improving the manuscript.

\section{Details of ethics approval}

Ethical approval was granted by the Medical Research Ethics Committee, UKM (GUP-2014-089).

\section{Conflicts of interest}

There is no conflict of interest to be declared.

\section{References}

1. Goldenberg RL, Culhane JF, Iams JD, et al. Epidemiology and causes of preterm birth. The Lancet. 2008. p. 75-84.

2. Dimes Mo, PMNCH, Children St, Born Too Soon: The Global Action Report on Preterm Birth Geneva: World Health Organization; 2012.

3. Liu L, Johnson HL, Cousens S, et al. Global, regional, and national causes of child mortality: an updated systematic analysis for 2010 with time trends since 2000. Lancet. 2012;379:2151-61.

4. Chang $\mathrm{HH}$, Larson J, Blencowe H, et al. Preventing preterm births: analysis of trends and potential reductions with interventions in 39 countries with very high human development index. The Lancet. 2013;381(9862):223-234.

5. Trends C. Preterm births: Indicators of Child \& Youth Well-being. 2015.

6. Preterm Birth: Causes, Consequences, and Prevention: The National Academies Press; 2007. 790 p.

7. Dekker GA, Lee SY, North RA, et al. Risk Factors for Preterm Birth in an International Prospective Cohort of Nulliparous Women. Plos One. 2012;7(7):e39154.

8. Han Z, Mulla S, Beyene J, et al. Maternal underweight and the risk of preterm birth and low birth weight: a systematic review and metaanalyses. Int J Epidemiol. 2011;40(1):65-101.

9. Xu H, Dai Q, Xu Y, et al. Time trends and risk factor associated with premature birth and infants deaths due to prematurity in Hubei Province, China from 2001 to 2012. BMC Pregnancy Childbirth. 2015;15(1):329.

10. Astolfi P, Zonta LA. Risks of preterm delivery and association with maternal age, birth order, and fetal gender. Human Reproduction. 1999;14(11):2891-2894.

11. A Perinatal Pathology View of Preterm Labor. 2000.

12. Stanford JB, Simonsen SE, Baksh L. Fertility treatments and adverse perinatal outcomes in a population-based sampling of births in Florida, Maryland, and Utah: a cross-sectional study. BJOG: An International Journal of Obstetrics \& Gynaecology. 2016;123(5):718-729.

13. BPKK. Perinatal Care Manual. In: Family Health Development Division M. 2013. p. 251.

14. NOR CRC. Preliminary Report of National Obsterics Registry, Jan 2011 - Dec 2012. Kuala Lumpur: National Obstetrics Registry \& Clinical Research Centre; 2015. 
15. Saigal S, Doyle LW. An overview of mortality and sequelae of preterm birth from infancy to adulthood. Lancet. 2008;371(9608):261-269.

16. WHO. WHO recommendations on interventions to improve preterm birth outcomes. 2015. 108 p.

17. WHO. Preterm birth. 2017

18. Mokuolu OA, Suleiman BM, Adesiyun OO, et al. Prevalence and determinants of pre-term deliveries in the University of Ilorin Teaching Hospital, Ilorin, Nigeria. Pediatr Rep. 2010;2(1):e3.

19. BPKK. Garispanduan Senarai Semak bagi Penjagaan Kesihatan Ibu dan Bayi Mengikut Sistem Kod Warna. Putrajaya: MOH; 2013.

20. List of average human height world wide. 2017.

21. DOSM. Malaysia Economics Statistics - Time Series. 2017

22. Lysikiewicz A, Bracero LA, Tejani N. Sonographically estimated feta weight percentile as a predictor of preterm delivery. The Journal of maternal-fetal medicine. 2001;10(1):44-47.

23. Sutan R, Yusof A. Syndemic Approach in Preventing Perinatal Near Miss before First Phase of Three Delay Model. Int J Pregn \& Chi Birth. 2017;2(4):00030.

24. Wagnew M, Dessalegn M, Worku A, et al. Trends of preeclampsia/ eclampsia and maternal and neonatal outcomes among women delivering in addis ababa selected government hospitals, Ethiopia: a retrospective cross-sectional study. The Pan African medical journal. 2016;25(Suppl 2):12.

25. Vural T, Toz E, Ozcan A, et al. Can anemia predict perinatal outcomes in different stages of pregnancy? Pakistan Journal of Medical Sciences. 2016;32(6):1354-1359.
26. Domple VK, Doibale MK, Nair A, et al. Assessment of maternal risk factors associated with low birth weight neonates at a tertiary hospital, Nanded, Maharashtra. Nigerian Medical Journal : Journal of the Nigeria Medical Association. 2016;57(1):37-43.

27. Shah R, Mullany LC, Darmstadt GL, et al. Incidence and risk factors of preterm birth in a rural Bangladeshi cohort. BMC Pediatrics. 2014;14(1):112.

28. Sutan R, Mohamed N, Tamil AM. Maternal Health-Seeking Behaviours in Preventing Preterm Delivery: A Case Control Study in Selangor. Journal of Gynecology and Women's Health. 2017;3(4).

29. Ingemarsson I. Gender aspects of preterm birth. BJOG: An International Journal of Obstetrics \& Gynaecology. 2003;110:34-38.

30. Stevenson D, Verter J, Fanaroff A, et al. Sex differences in outcomes of very low birthweight infants: the newborn male disadvantage. Arch Dis Child Fetal Neonatal Ed. 2000;83(3):F182-F5.

31. Chan BCP, Lao TTH. Maternal height and length of gestation: Does this impact on preterm labour in Asian women? Aust NZJ Obstet Gynaecol. 2009;49(4):388-392.

32. Hassan S, Vikanes A, Laine $\mathrm{K}$, et al. Building a research registry for studying birth complications and outcomes in six Palestinian governmental hospitals. BMC Pregnancy and Childbirth. 2017; 17(1):112

33. Commission E. The Use of Big Data in Public Health Policy and Research. 2017. 19 p.

34. Pereira APE, Leal MDC, daGama SGN, Domingues RMSM,Schilithz AOC, Bastos MH. Determining gestational age based on information from the Birth in Brazil study. Cad Saúde Pública. 2014;S1-S12. 